\title{
Traumatic tricuspid regurgitation in a pediatric patient: Is an early diagnosis possible?
}

\author{
Insuficiencia tricuspídea traumática en paciente pediátrico: ¿Es posible el diagnóstico \\ temprano?
}

Valentina Mescola, Pedro Castro-Cuba, Joaquín Pérez-Andreu*, Joaquín Fernández-Doblas, and Raúl F. Abella

Pediatric Cardiac Surgery Department, Hospital Universitario Vall d'Hebron. Barcelona, Spain

\section{Introduction}

Traumatic valvular injuries in the pediatric patient are isolated and heterogeneous episodes that are associated with high-energy trauma ${ }^{1-5}$. Initial clinical manifestations depend on the affected valve and severity of the injury and can go unnoticed in the vast majority of cases $^{4-7}$. In this context, tricuspid valve injury is the least frequent and is diagnosed lately due to its low clinical and hemodynamic initial repercussion ${ }^{4,8,9}$. The case is presented of a boy with severe tricuspid regurgitation secondary to chest trauma resulting from being run over by a motor vehicle.

\section{Clinical case}

A 9-year-old boy, who attended the authors' hospital with a history of months with mild effort dyspnea symptoms. Relevant personal history included closed chest and pelvic trauma (bilateral lung contusion, right pneumothorax, bilateral rib fractures, and left juxta-articular sacroiliac fracture) resulting from having been run over by a motor vehicle 12 months prior. His evolution had been favorable, with physical examination and cardiac auscultation without significant abnormalities at discharge.
At present, he had clinical symptoms consistent with right heart failure and low-intensity systolic murmur (II/VI) in the mesocardium. ECG showed previously-unknown incomplete right bundle branch block, with echocardiography revealing severe tricuspid regurgitation. Coaptation deficit secondary to anterior leaflet prolapse due to a ruptured tendinous cord that caused a wide jet with Coandă effect (15-mm vena contracta) that reached the atrial roof and generated systolic flow reversal in the suprahepatic veins was identified. The tricuspid annulus (30 mm; z-score, +1.6 ) and right ventricle (RVEDD, $23 \mathrm{~mm}$; z-score, +2) were dilated, with preserved systolic function (TAPSE, $25 \mathrm{~mm}$ ). Elective surgical repair was decided (Fig. 1).

Through midline sternotomy, under cardiopulmonary bypass with anterograde cardioplegia, and cardiac arrest, the tricuspid valve was explored through right atriotomy. The tricuspid valve showed prolapse of the anterior leaflet due to a ruptured tendinous cord of the anterior papillary muscle with a fissure at the level of the anteroseptal tricuspid valve commissure and annular dilation. The cord was reinserted into the head of the anterior papillary muscle with 6-0 Prolene ${ }^{\circledR}$, the rupture was closed with anteroseptal commissuroplasty plus annuloplasty according to De Vega's technique. The post-operative period was uneventful, and
Correspondence:

*Joaquín Pérez-Andreu

E-mail: joaquinperezandreu@gmail.com license (http://creativecommons.org/licenses/by-nc-nd/4.0/).

Date of reception: 03-04-2019

Date of acceptance: 14-06-2019
Arch Cardiol Mex (Eng). 2020;90(2):213-215 www.archivoscardiologia.com

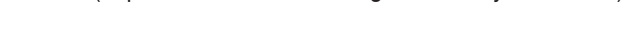




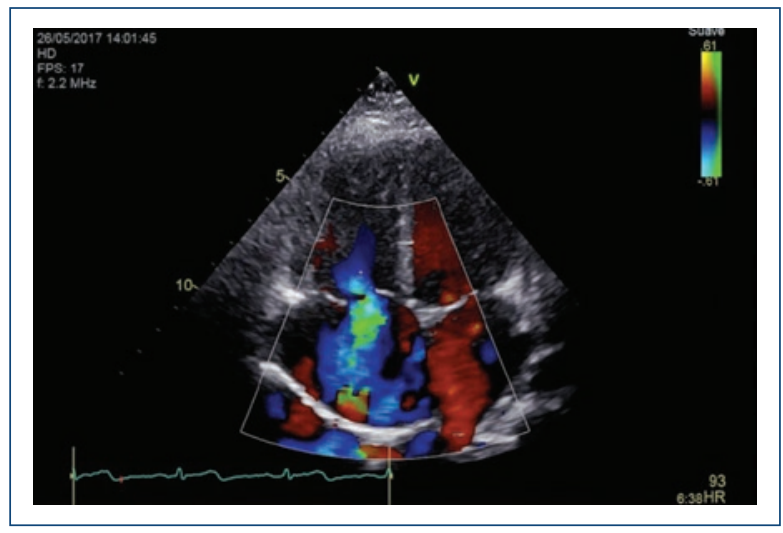

Figure 1. Pre-operative color Doppler echocardiography revealing severe tricuspid regurgitation due to anterior leaflet prolapse.

the boy was discharged after 7 days without residual valve failure.

Follow-up echocardiography at two years showed an absence of tricuspid regurgitation, without residual prolapse or restriction, with right ventricular size normalization (RVEDD, 18 mm; z-score, + 0.28) (Fig. 2).

\section{Discussion}

High-energy trauma, as in the case of traffic accidents, causes cardiac injuries in pediatric patients with an incidence of approximately $12.5 \%, 1,3.10$, with myocardial contusion being the most common injury $y^{1,3,6,11,12}$. Valvular involvement is rarer and usually occurs in the end-diastolic phase, which is a moment of the cardiac cycle, in which intracavitary pressures peak before the valve opening $4,5,12,13$. The most commonly affected valves are almost always the aortic valve, followed by the mitral, pulmonary, and finally, the tricuspid valve $e^{1,12}$. The most often described injury in atrioventricular valves is cord rupture, as in the presented case, followed by papillary muscle rupture and leaflets, involvement ${ }^{4,5,12}$.

In the case of heart valve injury, the simplest diagnostic method is auscultation since any acute valve injury precipitates the onset of a heart murmur. However, the suspected diagnosis, in the context of serious multiple trauma, may go unnoticed, especially when the injury has no significant hemodynamic repercussions, which results in most patients being diagnosed a posteriori when the progression of an untreated valve dysfunction starts showing signs of heart failure, newly-occurring heart murmurs or arrhythmias ${ }^{3-8,12,13}$. It is also possible that structural valve damage ultimately causes the definitive injury days later. In the presented

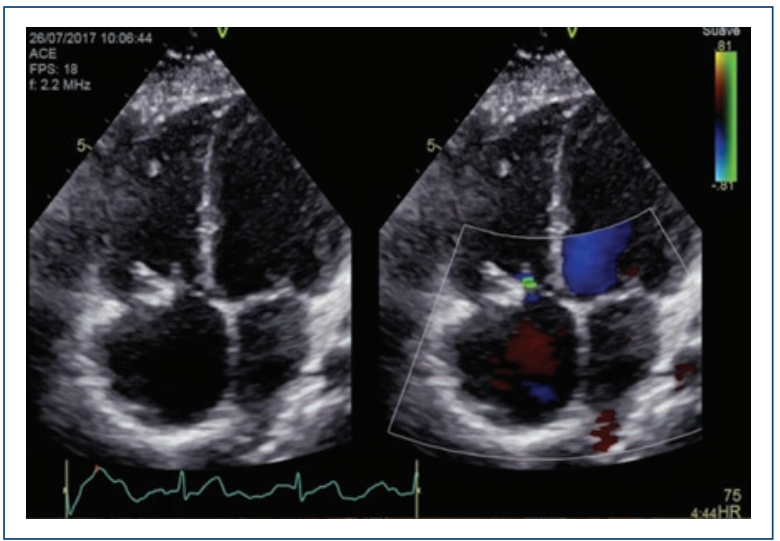

Figure 2. Post-operative color Doppler echocardiography showing minimal tricuspid regurgitation.

case, everything seems to indicate that the anterior papillary muscle tendinous cord avulsion occurred after discharge, and thus, it could only be diagnosed once secondary tricuspid regurgitation that was completely established.

Right side injuries are usually better tolerated since a sudden rise in right atrial venous pressure does not have a significant clinical impact due to systemic venous system capacitance. In contrast, acute mitral or aortic injuries produce pulmonary capillary pressure sudden elevation, with the appearance of acute lung edema and heart failure ${ }^{1,8,9}$.

Delayed diagnosis and treatment result in the appearance of other added defects, such as annuloaortic ectasia, progressive ventricular dilatation and dysfunction, and tachyarrhythmia due to cavity dilation. In these cases, evolution time determines the surgical technique and the possibilities of carrying out an effective repair to avoid valvular replacement, facilitate ventricular remodeling and heart failure signs disappearance $e^{4,5,8,9,12,14 .}$

Ultrasound in the multiple trauma patient (ECHOFAST, Focused Abdominal Sonography for Trauma Scan) $)^{15-17}$ allows making an initial evaluation in a few minutes and identifying anatomical structures of vital importance: the pleural space (hemopneumothorax), Morrison space, splenic fossa, Douglas space, and vascular central structures. However, its systematic use in the pediatric patient is not that standardized, and it is restricted, on many occasions, to arterial hypotension rapid differential diagnosis ${ }^{15-16}$.

Transthoracic echocardiography can provide much more information in the context of multiple trauma, even if it is in the form of secondary diagnoses. In the presented case, the physiological consequences at the 
ventricular and valvular level of the delay in the diagnosis of an injury on a structurally normal tricuspid valve are noted, and the fact that systematic echocardiographic workup would have provided data on unsuspected tricuspid valvular and subvalvular compromise stands out. Moreover, this analysis would enable carrying out an exhaustive study of the mechanisms causing the injury when planning a surgical repair as optimal as possible that avoids the need for valve replacement, even more so in a pediatric patient ${ }^{1,2,7,9,12,13}$. It could be interesting to include echocardiographic examination in the care of the multiple trauma pediatric patient even without clinical evidence of cardiac injury.

\section{Conclusion}

Systematic echocardiographic assessment in every pediatric patient, in the context of multiple trauma, might be indicated to diagnose valvular injuries that can otherwise go unnoticed, with the consequent risk of ventricular deterioration.

\section{Conflicts of interest}

The authors declare that they have no conflicts of interest.

\section{Funding}

This investigation has not received specific help from the public sector or commercial agencies or non-profit entities.

\section{Ethical disclosures}

Protection of people and animals. The authors declare that no experiments were performed on humans or animals for this investigation.
Confidentiality of data. The authors declare that they have followed the protocols of their work center on the publication of patient data.

Right to privacy and informed consent. The authors declare that no patient data appear in this article.

\section{References}

1. Zakynthinos E, Vassilakopoulos T, Routsi C, Roussos C, Zakynthinos S. Early- and late-onset atrioventricular valve rupture after blunt chest trauma: the usefulness of transesophageal echocardiography. J Trauma. 2002; 52: 990-6.

2. Li Looi J, Pui-Wai Lee A, Wong R, Yu C. 3D Echocardiography for traumatic tricuspid regurgitation. JACC Cardiovasc Imaging. 2012; 5:1285-7.

3. Hodge A, Forbus G, Yen Hsia T. Concomitant repair of mitral valve papillary muscle rupture and tricuspid valve avulsion in a pediatric patient after a motor vehicle collision. JECT. 2009;41:180-2.

4. Dounis G, Matsakas E, Poularas J, Papakonstantinnou K, Kalogeromitros A, Karabinis A. Traumatic tricuspid insufficiency: a case report with a review of the literatura. Eur J Emerg Med. 2002;9:258-61.

5. Loar R, Maskatia S, Scheller E, Mott A, Adachi I, Fraser C. Complex surgical repair of a flail tricuspid valve after chest wall trauma in a pediatric patient. Ann Thorac Surg. 2016;101:e65-7.

6. Chirillo F, Totis O, Cavarzerani A, Bruni A, Famia A, Sarpellon M, et al Usefulness of transthoracic and transoesophageal echocardiography in recognition and management of cardiovascular injuries after blunt chest trauma. Heart. 1996;75:301-6.

7. Nishimura K, Okayama H, Inoue K, Saito M, Nagai T, Suzuki J, et al Visualization of traumatic tricuspid insufficiency by three-dimensional echocardiography. J Cardiol. 2010, 55:143-6.

8. Fujiwara K, Hisaoka T, Komai H, Nishimura Y, Yamamoto S, Okamura Y Successful repair of traumatic tricuspid valve regurgitation. Jpn J Thorac Cardiovasc Surg. 2005; 53:259-62.

9. Ma W, Luo G, Sun H, Xu J, Hu S, Zhu X. Surgical treatment of traumatic tricuspid insufficiency: experience in 13 cases. Ann Thorac Surg. 2010;90:1934-8.

10. Dowd D, Krug S. Pediatric blunt cardiac injury: epidemiology, clinical features, and diagnosis. J Trauma. 1996;40:61-7.

11. Lancey $R$, Monahan T. Correlation of clinical characteristics and outcomes with injury scoring in blunt cardiac trauma. J Trauma. 2003;54:509-15.

12. Stoica B, Paul S, Tanase I, Negoi I, Runcanu A, Beuran M. Traumatic tricuspid valve rupture after blunt chest trauma - A case report and review of the literature. Chirurgia. 2015;110:467-70.

13. Aris A, Delgado L, Montiel J, Subirana M. Multiple intracardiac lesions after blunt chest trauma. Ann Thorac Surg. 2000;70:1692-4

14. Sakurai S, Takenaka K, Shiojima I, Watanabe F, Sonoda M, Uno K, et al. Traumatic tricuspid insufficiency. Echocardiography. 2001;18:303-4.

15. Pershad J, Myers S, Plouman C, Rosson C, Elam K, Wan J, et al. Bedside limited echocardiography by the emergency physician Is accurate during evaluation of the critically ill patient. Pediatrics. 2004;114;e667-71.

16. Scalea T, Rodríguez A, Chiu W, Brenneman F, Fallon W, Kato K, et al. Focused assessment with sonography for trauma (FAST): results from an international consensus conference. J Trauma. 1999;46:466-72.

17. Holmes JF, Kelley KM, Wootton-Gorges SIL, Utter GHP, Abramson IPP, Rose JSS, et al. Effect of abdominal ultrasound on clinical care, outcomes, and resource use among children with blunt torso trauma: a randomized clinical trial. JAMA. 2017;317:2290-6. 